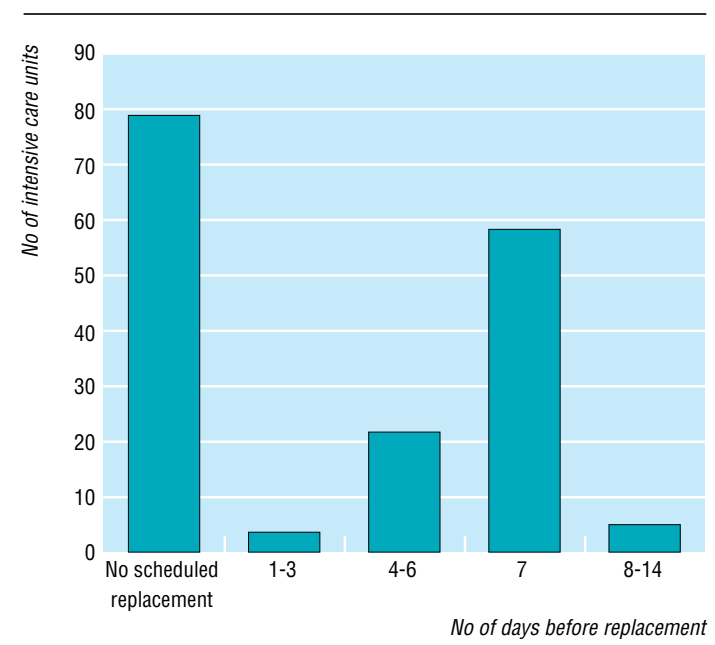

Scheduled replacement of central venous catheters by 165 of the 169 intensive care units in mainland Britain listed in Directory of Emergency and Special Care Units 1996

tral venous catheters should not be routinely replaced as a means of preventing catheter related infections. ${ }^{5}$ This guideline is strongly recommended for all hospitals and is supported by well designed studies. ${ }^{5}$

Fifty eight of the 86 units that routinely replaced central venous catheters removed them at 7 days. This practice was arbitrary, pragmatic, or influenced by conclusions from uncontrolled data. ${ }^{2}$ The incidence of sepsis related to the catheter is not increased when central venous catheters are replaced after more than three days. ${ }^{3}{ }^{4}$ Scheduled replacement has recognised complications and is demanding of staff and resources. Despite the additional risks, the lack of evidence of benefit, and the extra costs entailed, routine scheduled replacement is still widely practised in many intensive care units in mainland Britain.

Contributors: AMC and JLH organised and supervised the study, interpreted the data, and wrote the paper. AL, KR, and PK collected the data and assisted with data entry and analysis. AMC is guarantor for the paper.

Funding: None.

Conflict of interest: None.

1 Ryan DW, Gould FK. Central venous line sepsis. Anaesthesia 1997;52:286-7.

2 Ullman RF, Gurevich I, Schoch PE, Cunha BA. Colonization and bacteremia related to duration of triple-lumen intravascular catheter placement. Am J Infect Control 1990;18:201-7.

3 Cobb DK, High KP, Sawyer RG, Sable CA, Adams RB, Lindley DA, et al A controlled trial of scheduled replacement of central venous and pulmonary artery catheters. N Engl J Med 1992;327:1062-8.

4 Eyer S, Brummitt C, Crossley K, Siegel R, Cerra F. Catheter-related sepsis: prospective randomized study of three methods of long-term catheter maintenance. Crit Care Med 1990;18:1073-9.

5 Hospital infection control practices advisory committee. Part II. Recommendations for the prevention of intravascular device-related infections. Am J Infect Control 1996;24:277-93.

(Accepted 3 December 1997)

\title{
Questionnaire study of effect of sex and age on the prevalence of wheeze and asthma in adolescence
}

\author{
Andrea Venn, Sarah Lewis, Marie Cooper, Jennifer Hill, John Britton
}

In early childhood wheezing and asthma are more common in boys than girls. ${ }^{1}$ This difference has either disappeared or reversed by early adulthood, ${ }^{2}$ although the age at which the change occurs is unclear. We therefore measured the age and sex specific prevalence of self reported wheeze and diagnosed asthma in 11-16 year old children attending secondary schools in the Nottingham area.

\section{Subjects, methods, and results}

In 1996 we completed a prevalence survey of all pupils attending 44 secondary schools in a defined postcode area in and around Nottingham. Questionnaires about lifetime and current wheeze and asthma diagnosed by a doctor (appendix) were distributed to pupils for self completion during school time. Data were collected on 27826 pupils (over 80\% of registered pupils) aged $11-16$ years, $51 \%$ of whom were boys. Parental responses to the same questions were obtained for a 1 in 4 random subsample of 3894 pupils (59\% response).

The self reported lifetime prevalence of wheeze was $30.1 \%(8317 / 27632)$, with $19.0 \%(5253 / 27668)$ of children reporting having wheezed in the past year. Of the children with current wheeze who also provided information on asthma $3527 / 5154(68 \%)$ had had asthma diagnosed by a doctor at some time. Wheeze and diagnosed asthma were both significantly more prevalent in girls than boys (relative risk for wheeze in the past year 1.24 (95\% confidence interval 1.18 to 1.30) (figure); full data are available in a table on our website). However, this sex difference was dependent on age. At 11 years wheeze was more common in boys, but thereafter the prevalence of wheeze decreased with age in boys $\left(\chi^{2}\right.$ test for trend $\left.=23.2, \mathrm{P}<0.0001\right)$ and increased with age in girls $\left(\chi^{2}=20.4, \mathrm{P}<0.0001\right)$, the sex reversal occurring at age 12. Inclusion of an age-sex interaction term in the multiple logistic regression model confirmed the significance of this effect $(\mathrm{P}<0.0001)$.

Analysis of parental responses gave lower prevalences of wheeze (lifetime 25.6\% (994/3878), past year $16.4 \%(636 / 3880))$. Sex reversal in wheezing $(\mathrm{P}<0.01$ for age-sex interaction term) occurred at age 13, after which prevalence was relatively constant.

\section{Comment}

The male predominance of wheezing during the first decade of life is reversed around the time of puberty due to an increase in reported wheeze in girls and a fall

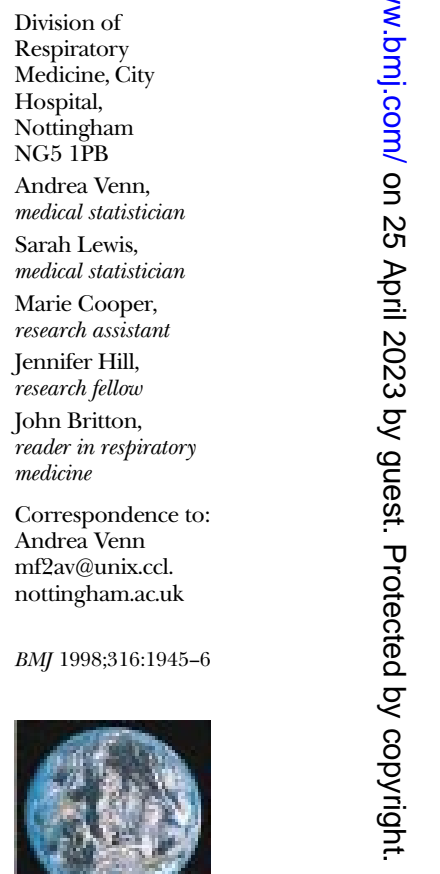

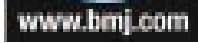




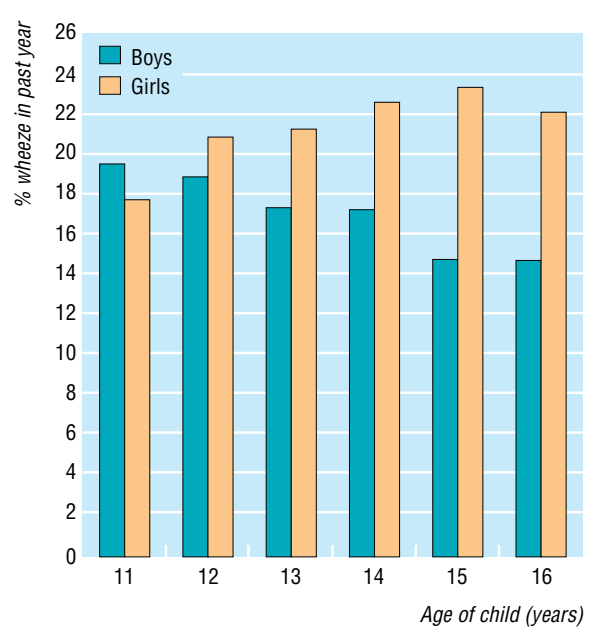

\begin{tabular}{rl|l|l|l|l|l} 
Prevalence in boys (\%) & 19.0 & 18.5 & 17.1 & 17.0 & 14.5 & 14.5 \\
\hline Prevalence in girls (\%) & 17.2 & 20.4 & 20.9 & 22.4 & 23.0 & 22.0 \\
\hline Relative risk (boys $v$ girls) & 1.10 & 0.91 & 0.82 & 0.76 & 0.63 & 0.66
\end{tabular}

Self reported prevalence of wheeze in past year by age and sex

in boys. A tendency for girls to overreport asthma symptoms and boys to deny them may have overestimated the size of the sex difference. However, the effect persisted when we used parental responses and also when we restricted the analysis to current wheezers with a doctor's diagnosis of asthma, both of which measures may be less affected by sex. We found no difference in response rates among boys or girls of different ages except for slightly lower rates by both sexes in year 11, which would not have affected the overall trend. Parental response rates did fall with age, but this does not appear to have biased the estimates since the pattern of parent reported prevalence is similar to that of self reported prevalence. It therefore seems unlikely that the sex effect is solely the result of reporting or selection bias.

Hormonal changes occurring in early puberty could have a role in the changing prevalences. Troisi et al reported a positive dose-response relation between oestrogen use and the risk of adult onset asthma in women. ${ }^{3}$ Also there is evidence that girls are more likely than boys to develop asthma in adolescence, ${ }^{4}$ which could be hormone related or due to girls experiencing different exposures to triggers for wheeze at this age, such as smoking. The decrease in wheezing prevalence in boys may be related to the increase in size of airways, which are on average smaller than those of girls in infancy. ${ }^{5}$ The effects of hormones and other factors operating during early adolescence on measures of airway inflammation and other markers of asthma deserve further investigation.

We thank Peter Housden, director of education; Julia Swan, assistant director; and Tony Dessent, senior assistant director of Nottinghamshire County Council for their support of the study and all the teaching and secretarial staff at the participating schools who made the survey work possible. We also thank Marilyn Antoniak, Andrea Goldsmith, Chris Smith, and Nicola Williamson for help with data collection.

Contributors: SL, JH, and JB designed the study. AV, SL, JH, and MC collected the data. AV analysed the data and wrote the paper. All authors helped with interpreting the data and preparing the manuscript. JB is guarantor for the paper.

Funding: National Asthma Campaign and Department of Health.

Conflict of interest: None.

\section{Appendix: Respiratory questions asked}

- Have you ever had attacks of wheezing in the chest? (a noisy whistling sound from the chest, not the throat, causing tightness and breathlessness)

- Have you had any wheezing attacks in the last year?

- Have you ever been told by a doctor that you have asthma?

1 Luyt DK, Burton PR, Simpson H. Epidemiological study of wheeze, doctor diagnosed asthma, and cough in preschool children in Leicestershire. BMJ 1993;306:1386-90.

2 Anderson HR, Pottier AC, Strachan DP. Asthma from birth to age 23: incidence and relation to prior and concurrent atopic disease. Thorax 1992;47:537-42.

3 Troisi RJ, Speizer FE, Willett WC, Trichopoulos D, Rosner B. Menopause, postmenopausal estrogen preparations and the risk of adult-onset asthma. A prospective cohort study. Am J Respir Crit Care Med 1995; 152:1183-8.

4 Schachter J, Higgins MW. Median age at onset of asthma and allergic rhinitis in Tecumseh, Michigan. J Allergy Clin Immunol 1976;57:342-51.

5 Tepper RS, Morgan WJ, Cota K, Wright A, Taussig LM. Physiological growth and development of the lung during the first year of life. Am Rev Respir Dis 1986;134:513-9.

(Accepted 16 December 1997)
Cardiovascular

Beth Israel

Deaconess Medical

Center, Boston MA

02215, USA

Todd B Seto,

fellow, cardiovascular

disease

Murray A

Mittleman,

assistant professor of

medicine

continued over

BMJ 1998;316:1946-7
A seasonal variation in cardiac mortality has been noted in both the northern ${ }^{12}$ and southern ${ }^{3}$ hemispheres, with higher death rates during winter than summer. Previous studies reporting seasonal variation in mortality from coronary artery disease examined data from regions with distinct seasonal changes in temperature. To determine whether seasonality in mortality exists in a tropical climate with little variation in temperature we examined the monthly mortality from coronary artery disease among residents of Hawaii.

\section{Methods and results}

Hawaii consists of six main islands, with a population of 1.1 million. ${ }^{4}$ We obtained monthly rates of deaths from coronary artery disease (ICD-9 410-414) as recorded on death certificates during 1984-93 from the state of Hawaii. All non-residents of Hawaii were excluded. Because the likelihood of a diagnosis of a respiratory infection might vary by season, we used mortality from respiratory infection (ICD-9 480-487) as a proxy for incidence of respiratory infection. We 